Journal of Animal and Veterinary Advances 11 (19): 3635-3640, 2012

ISSN: $1680-5593$

(C) Medwell Journals, 2012

\title{
Surveillance and Molecular Characterization of Vibrio parahaemolyticus from Different Sources in Zhoushan Islands, China
}

\author{
Lihua Tang, Hongling Wang, Yun Luo, Lijun Huang, Hongxia Gong, Hui Zhang and Jianyue Wang \\ Zhoushan Center for Disease Control and Prevention, Zhoushan, 256 Wengshan Road, \\ Dinghai District, Zhoushan, 316021 Zhejiang, China
}

\begin{abstract}
V$. parahaemolyticus is one of the most important foodborne pathogens in China and other countries. In this study, researchers investigated the contamination of $V$. parahaemolyticus in shellfish during different seasons in Zhoushan islands. Meanwhile, researchers reported the prevalence, molecular characterization and virulence genes of $V$. parahaemolyticus from shellfish and clinical patients. In shellfish, the positive rate was $85,80,75$ and $10 \%$, respectively in different seasons from Spring to Winter. Among the shellfish isolates, there was no $\mathrm{tdh}^{+}$strains and only $4 \% \mathrm{trh}^{+}$strains. The prevalence of $V$. parahaemolyticus in clinical samples was 36 and $77.78 \%$ of clinical strains were $\mathrm{tdh}^{+}$, toxRS $/ \mathrm{new}^{+}$, orf $8^{+}$and $5.56 \%$ clinical strains were $\mathrm{trh}^{+}$. In $80 \%$ similarity, the total of 53 strains could be divided into twenty nine types. Most of the shellfish strains present various patterns with far relationship while all the pandemic strains from clinical samples belonged to same clone group with $82.8 \%$ similarity. The $\mathrm{tdh}^{+}$, toxRS $/ \mathrm{new}^{+}$and orf $8^{+}$strains were the main epidemic strains in Zhoushan islands.
\end{abstract}

Key words: $V \cdot$ parahaemolyticus, virulence gene, molecular typing, island, shellfish, strains

\section{INTRODUCTION}

V. parahaemolyticus is a water and foodborne pathogen, commonly present in sea water and marine product all over the world. Research has suggested that the shellfish were seriously polluted by $V$. parahaemolyticus and humans often get infection by consuming raw or undercooked shellfish. In the USA, raw oysters are the most important vehicles for transmission of $V$. parahaemolyticus. Zhoushan city is a island city with abundant shellfish and the infection caused by this bacterium is the most important cause of foodborne disease. In this study, researchers investigated the contamination of $V$. parahaemolyticus in the shellfish in Zhoushan. In addition, researchers analyzed the serovar distrubution, the presence of virulence genes and molecular typing of all strains isolated from shellfish and clinical samples in Zhoushan city.

\section{MATERIALS AND METHODS}

Shellfish samples: Shellfish food samples $(n=80)$ were collected from aquatic food markets $(n=5)$ in Zhoushan city. Of the 80 samples, shellfish food normally included Scapharca subcrenata, razor clam, clam, Moerella iridescens, mussels, oyster, Whelk, etc. which were bred with artificial seawater. Considering the influence of seawater temperature, samples were collected in different season in 2009.

Bacterial isolates from clinical patients: There were 18 strains from clinical patients, in which 7(VP51-VP57) isolates from patients of outbreaks and 11 (VP58-VP68) were from sporadic diarrhea outpatients of foodborne diseases from hospitals. All strains were isolated from May to September in 2009.

Identification of $V$. parahaemolyticus: About $25 \mathrm{~g}$ of food samples was added to $225 \mathrm{~mL}$ sodium chloride violet purple enrichment broth (or $1 \mathrm{~g}$ feces samples added to $9 \mathrm{~mL}$ of the broth) and incubated for $9 \mathrm{~h}$. A loop of the enriched broth was streaked onto Vibrio Chromogrnic medium (CHROMagar, Paris, France) and TCBS. Typical colonies were confirmed as $V$. parahaemolyticus by ATB ID32 E kits.

Serogrouping: About 11 of Serum $O$ and some common Serum K was bought from Denka Seiken, Tokyo, Japan. Following manufacturer's instructions, an aliquot of the cell suspension in normal saline was boiled for $2 \mathrm{~h}$ and

Corresponding Author: Jianyue Wang, Zhoushan Center for Disease Control and Prevention, Zhoushan, 256 Wengshan Road, Dinghai District, Zhoushan, 316021 Zhejiang, China 


\begin{tabular}{|c|c|c|c|c|}
\hline Primers & Target gene & Sequence $\left(5^{\prime}-3^{\prime}\right)$ & Amplicon size (bp) & References \\
\hline tdh-F & $t d h$ & ATATCCATGTTGGCTGCATTC & 531 & Chao et al. (2009) \\
\hline tdh-R & & TTATTGTTGATGTTTACATTCAAAA & & \\
\hline trh-F & $\operatorname{trh}$ & ATGAAACTAAAACTCTACTTTGC & 553 & Chao et al. (2009) \\
\hline $\begin{array}{l}\text { trh-R } \\
\text { orf8-F }\end{array}$ & orfs & $\begin{array}{l}\text { TTAATTTTGTGACATACATTCAT } \\
\text { GTTCGCATACAGTTGAGG }\end{array}$ & 700 & Nasu et al. (2000) \\
\hline orf8-R & & AAGTACAGCAGGAGTGAG & & \\
\hline toxRS/new-F & toxRS/new & TAATGAGGTAGAAACA & 651 & Matsumoto et al. (2000) \\
\hline
\end{tabular}

used for serotyping based on $\mathrm{O}$ antigen. The remaining cell suspension (not boiled) was used for serotyping based on $\mathrm{K}$ antigen.

PCR for $\boldsymbol{t} \boldsymbol{t} \boldsymbol{h}, \boldsymbol{t} \boldsymbol{h}$, orf 8 and $t o x R S / n e w$ genes: Bacteria were grown overnight at $37^{\circ} \mathrm{C}$ on a tryptic soy agar plate. The genetic DNA was extracted from overnight cultures using TIANamp Bacteria DNA kit (Tiangen Biotech (Beijing) Co., Ltd. Beijing, China) following manufacturer's instructions.

Four sets of oligonucletide primers (tdh-F/tdh-R, trh-F/trh-R, orf8-F/ orf8-R and toxRS/new-F/ toxRS/new-R) (Table 1) were referred from document (Chao et al., 2009) to detect the presence of virulence genes in the $V$. parahaemolyticus isolates. PCR assays testing was performed as described earlier (Chao et al., 2009). Briefly, $25 \mathrm{ng}$ purified total DNA, 25 pmol primer 4, 1.5U Taq polymerase, $10 \mathrm{x}$ PCR buffer containing $20 \mathrm{mM} \mathrm{MgCl}_{2}$ and $0.125 \mathrm{mM}$ each $\mathrm{dNTP}$ were used for each amplification reaction. The reactions were performed with a MyCyclerTM Thermal Cycler (BIO-RAD) as followings for tdh and trh amplification: the amplification conditions were one cycle of $94^{\circ} \mathrm{C}$ for $3 \mathrm{~min}$, followed by 30 cycles of denaturation at $94^{\circ} \mathrm{C}$ for $55 \mathrm{sec}$, annealing at $50^{\circ} \mathrm{C}$ for $50 \mathrm{sec}$ and extension at $72^{\circ} \mathrm{C}$ for $2 \mathrm{~min}$ followed by a final extension at $72^{\circ} \mathrm{C}$ for $10 \mathrm{~min}$. For amplification of orf 8 and toxRS/new, the conditions were one cycle of $94^{\circ} \mathrm{C}$ for $3 \mathrm{~min}$ followed by 35 cycles of denaturation at $94^{\circ} \mathrm{C}$ for $30 \mathrm{sec}$, annealing at $58^{\circ} \mathrm{C}$ for $30 \mathrm{sec}$ and extension at $72^{\circ} \mathrm{C}$ for $1 \mathrm{~min}$ followed by a final extension at $72^{\circ} \mathrm{C}$ for $5 \mathrm{~min}$. The PCR product was visualized by electrophoresis in a $1.5 \%$ agarose gel and documented using a GelDoc System (Bio-Rad Laboratories).

PFGE: Pulsed-Field Gel Electrophoresis (PFGE) of NotIdigested DNA of $V$. parahaemolyticus was performed using a standardized protocol as described earlier (Kam et al., 2008). XbaI-digested Salmonella Braenderup reference standard strain, H9812 was used as a molecular size marker. Following electrophoresis, gels were stained with ethidium bromide $\left(10 \mathrm{mg} \mathrm{mL}^{-1}\right)$ and photographed under UV transillumination. The clonal relatedness among the strains was determined using the Dice coefficient and cluster analysis was carried out using Unweighted-Pair
Grouping with Mathematical Averaging (UPGMA) and PFGE profiles of $V$. parahaemolyticus strains were drawed by using Quantity One ${ }^{\mathrm{TM}}$ Software.

\section{RESULTS AND DISCUSSION}

V. parahaemolyticus obtained from shellfish: The prevalence of $V$. parahaemolyticus in shellfish was $85 \%$ $(17 / 20)$ in Spring, 80\% (16/20) in Summer, 75\% (15/20) in Autumn and $10 \%(2 / 20)$ in Winter. There was no significantly difference between the Spring, Summer and Autumn. While the positive rate in Winter $(10 \%)$ was significantly different from foregoing seasons (Table 2).

Servars of all $68 \mathrm{~V}$. parahaemolyticus isolates: About 50 strains from shellfish (except 1 isolate cannot be recognized) belong to 7 serogroups. The $\mathrm{O} 1, \mathrm{O} 2, \mathrm{O} 3, \mathrm{O} 4$, 05,010 and 011 accounted for $22.0 \%(11 / 50), 10.0 \%$ $(5 / 50), 2.0 \%(1 / 50), 14.0 \%(7 / 50), 6.0 \%(3 / 50), 22.0 \%(11 / 50)$ and $22.0 \%(11 / 50)$ of all foodborn isolates, respectively. The O1, O4, O10 and O11 accounted for 80\% (40/50) of food isolates. About $72.2 \%(13 / 18)$ of clinical isolates belong to $\mathrm{O} 3$ serogroup (O3K6); 22.2\% (4/18) of them belong to $\mathrm{O} 1$ serogroup; $5.6 \%(1 / 18)$ belong to $\mathrm{O} 4$ serogroup (Table 3).

PCR for virulent genes: Only 2 strains of all 50 isolates detected from shellfish were $t r h$ gene positive and other 18 strains were negative of all 4 virulent genes. About 14 strains of 18 clinical isolates carry the virulent genes (tdh, toxRS/new and orf8); 1 strain of them was trh gene positive; 3 strains of them were negative of all 4 virulent genes (Table 4).

PFGE: The electrophoresis migration pattern of NotI-digested fragments of the chromosomal DNA of 53 strains of $V$. parahaemolyticus was obtained by PFGE. The other 15 strains were degraded including 7 strains from shellfish isolates and 8 strains from clinical isolates.

Analysis of PFGE patterns revealed that various types have a major difference, the same serotype strains could obtain different PFGE draft while different serotype strains could obtain same PFGE draft. In $80 \%$ similarity, the 53 strains could be divided into twenty nine types 
(P1-P29), of which the 43 shellfish strains could be divided into twenty six types and 10 clinical strains could be divided into four types (Fig. 1, Table 5).

$V$. parahaemolyticus is widely distributed in marine environments and is associated with gastroenteritis cases caused by consumption of seafood. Because shellfish usually be consumed by raw and undercooked in Zhoushan island and is often associated with food poisoning caused by $V$. parahaemolyticus, researchers surveyed the contamination of $V$. parahaemolyticus in Zhoushan island. Several studies showed that the contamination level of $V$. parahaemolyticus in seafood products is associated to the water temperatures: it is more likely to isolate $V$. parahaemolyticus in seafood products in the Summer than in the Winter (Kaneko and Colwell, 1973; Depaola et al., 1990; Cook et al., 2002). In this study, results showed that the contamination of
$V \cdot$ parahaemolyticus on shellfish in Zhoushan island was seriously, especially in Spring, Summer and Autumn, the positive rate was high to $80 \%$ while the positive rate in winter was $10 \%$, significantly lower than other seasons. Therefore, the first three seasons were pandemic time of diarrhea infected by $V$. parahaemolyticus. Consequently, health supervisinon department should strengthen the supervision on seafood snacks and restaurants serving with aquatic products during the pandemic time.

Table 2: Positive rate of $V$. parahaemolyticus detected from shellfish in different seasons

\begin{tabular}{lcccc}
\hline $\begin{array}{l}\text { Seasons } \\
\text { (month) }\end{array}$ & $\begin{array}{c}\text { Water } \\
\text { Temp. }\left({ }^{\circ} \mathrm{C}\right)\end{array}$ & $\begin{array}{c}\text { No. of } \\
\text { samples }\end{array}$ & $\begin{array}{c}\text { No. of } \\
\text { strains }\end{array}$ & $\begin{array}{c}\text { Positive } \\
\text { rate (\%) }\end{array}$ \\
\hline Spring (Apr.) & 14 & 20 & 17 & 85.0 \\
Summer (Aug.) & 22 & 20 & 16 & 80.0 \\
Autumn (Nov.) & 12 & 20 & 15 & 75.0 \\
Winter (Jan.) & 4 & 20 & 2 & 10.0 \\
Total & 88 & 80 & 50 & 62.5 \\
\hline
\end{tabular}

Table 3: Serotyping for $V$. parahaemolyticus in 68 isolates

\begin{tabular}{|c|c|c|c|c|c|c|c|c|}
\hline \multirow[b]{2}{*}{ Source of isolates } & \multicolumn{8}{|c|}{ Serotype (No. of isolates (\%)) } \\
\hline & $\mathrm{O} 1$ & $\mathrm{O} 2$ & $\mathrm{O} 3$ & $\mathrm{O} 4$ & $\mathrm{O} 5$ & $\mathrm{O} 10$ & $\mathrm{O} 11$ & KUT \\
\hline Shellfish isolates & $11(22.0)$ & $5(10.0)$ & $1(2.0)$ & $7(14.0)$ & $3(6.0)$ & $11(22.0)$ & $11(22.0)$ & $1(2.0)$ \\
\hline Clinical isolates & $4(22.2)$ & $0(0.0)$ & $13(72.2)$ & $1(5.6)$ & $0(0.0)$ & $0(0.0)$ & $0(0.0)$ & $0(0.0)$ \\
\hline Total & $15(22.1)$ & $5(7.4)$ & $14(20.6)$ & $8(11.8)$ & $3(4.4)$ & $11(16.2)$ & $11(16.2)$ & $1(1.5)$ \\
\hline
\end{tabular}

Table 4: Virulent gene of $V$. parahaemolyticus in 68 isolates

\begin{tabular}{|c|c|c|c|c|c|}
\hline \multirow[b]{2}{*}{ Source of isolates } & \multirow[b]{2}{*}{ No. of isolates } & \multicolumn{4}{|c|}{ Virulent genes } \\
\hline & & $t d h$ & $\operatorname{trh}$ & orfs & toxRS/neu \\
\hline \multirow{2}{*}{ Shellfish isolates } & 48 & - & - & - & - \\
\hline & 2 & - & + & - & - \\
\hline \multirow[t]{3}{*}{ Clinical isolates } & 14 & + & - & + & + \\
\hline & 1 & - & + & - & - \\
\hline & 3 & - & - & - & - \\
\hline
\end{tabular}

Table 5: Virulent, pandemic and molecular subtype characteristics of 50 shellfish isolates and 18 clinical isolates

\begin{tabular}{|c|c|c|c|c|c|c|c|}
\hline \multirow[b]{2}{*}{ Serotype } & \multirow[b]{2}{*}{ No. of isolates } & \multicolumn{4}{|c|}{ Virulent genes } & \multirow[b]{2}{*}{ Isolates number (PFGE types) } & \multirow[b]{2}{*}{ Source of isolates (No. of isolates) } \\
\hline & & $t d h$ & $\operatorname{trh}$ & orfs & toxRS/new & & \\
\hline$\overline{\mathrm{O} 1}$ & 11 & - & - & - & - & $\begin{array}{l}\text { 2(P15), 7(P12), 12(P20), 13(P04), 21(P15), } \\
\text { 29(P12), 38(P28), 43(P13), 45(P01), } \\
\text { 58(P10), 67(P21) }\end{array}$ & $\begin{array}{l}\text { Shellfish (9), } \\
\text { Clinical (2) }\end{array}$ \\
\hline & 3 & - & + & - & - & 49(P23), 50(P23), 64(P19) & Shellfish (2), clinical (1) \\
\hline & 1 & + & - & + & + & $65(\mathrm{P} 17)$ & Clinical (1) \\
\hline $\mathrm{O} 2$ & 5 & - & - & - & - & $8\left(^{*}\right), 19(\mathrm{P} 04), 28(\mathrm{P} 08), 33(\mathrm{P} 08), 37(\mathrm{P} 27)$ & Shellfish (5) \\
\hline $\mathrm{O} 3$ & 1 & - & - & - & - & 1(P14) & Shellfish (1) \\
\hline & 13 & + & - & & + & $\begin{array}{l}51(\mathrm{P} 17), 52(\mathrm{P} 17), 53(\mathrm{P} 17), 54\left(^{*}\right), 56\left(^{*}\right), \\
57\left(^{*}\right), 59(\mathrm{P} 17), 60(\mathrm{P} 17), 61\left(^{*}\right), 62(\mathrm{P} 17), \\
\left.63^{*}\right), 66\left(^{*}\right), 68\left(^{*}\right)\end{array}$ & Clinical (13) \\
\hline $\mathrm{O} 4$ & 8 & - & - & - & - & $\begin{array}{l}\text { 3(P18), 17(P25), 26(P14), 36(P17), } \\
39(\mathrm{P} 05), 47\left(^{*}\right), 48(\mathrm{P} 22), 55\left({ }^{*}\right)\end{array}$ & $\begin{array}{l}\text { Shellfish (7) } \\
\text { Clinical (1) }\end{array}$ \\
\hline 05 & 3 & - & - & - & - & 27(P12), 41(P02), 44(P07) & Shellfish (3) \\
\hline $\mathrm{O} 10$ & 11 & - & - & - & - & $\begin{array}{l}4\left({ }^{*}\right), 6(\mathrm{P} 04), 9(\mathrm{P} 10), 10(\mathrm{P} 06), 15(\mathrm{P} 05), \\
16(\mathrm{P} 18), 20(\mathrm{P} 09), 24(\mathrm{P} 26), 25(\mathrm{P} 04), \\
34(\mathrm{P} 24), 35(\mathrm{P} 03)\end{array}$ & Shellfish (11) \\
\hline O11 & 11 & - & - & - & - & $\begin{array}{l}5\left({ }^{*}\right), 11(\mathrm{P} 25), 14(\mathrm{P} 16), 18(\mathrm{P} 14), 22\left(^{*}\right), \\
23(\mathrm{P} 01), 30(\mathrm{P} 12), 32(\mathrm{P} 11), 40(\mathrm{P} 29), \\
42(*), 46(\mathrm{P} 13)\end{array}$ & Shellfish (11) \\
\hline KUT & 1 & - & - & - & . & $31\left(^{*}\right)$ & Shellfish (1) \\
\hline
\end{tabular}

*Degraded strains by PFGE 


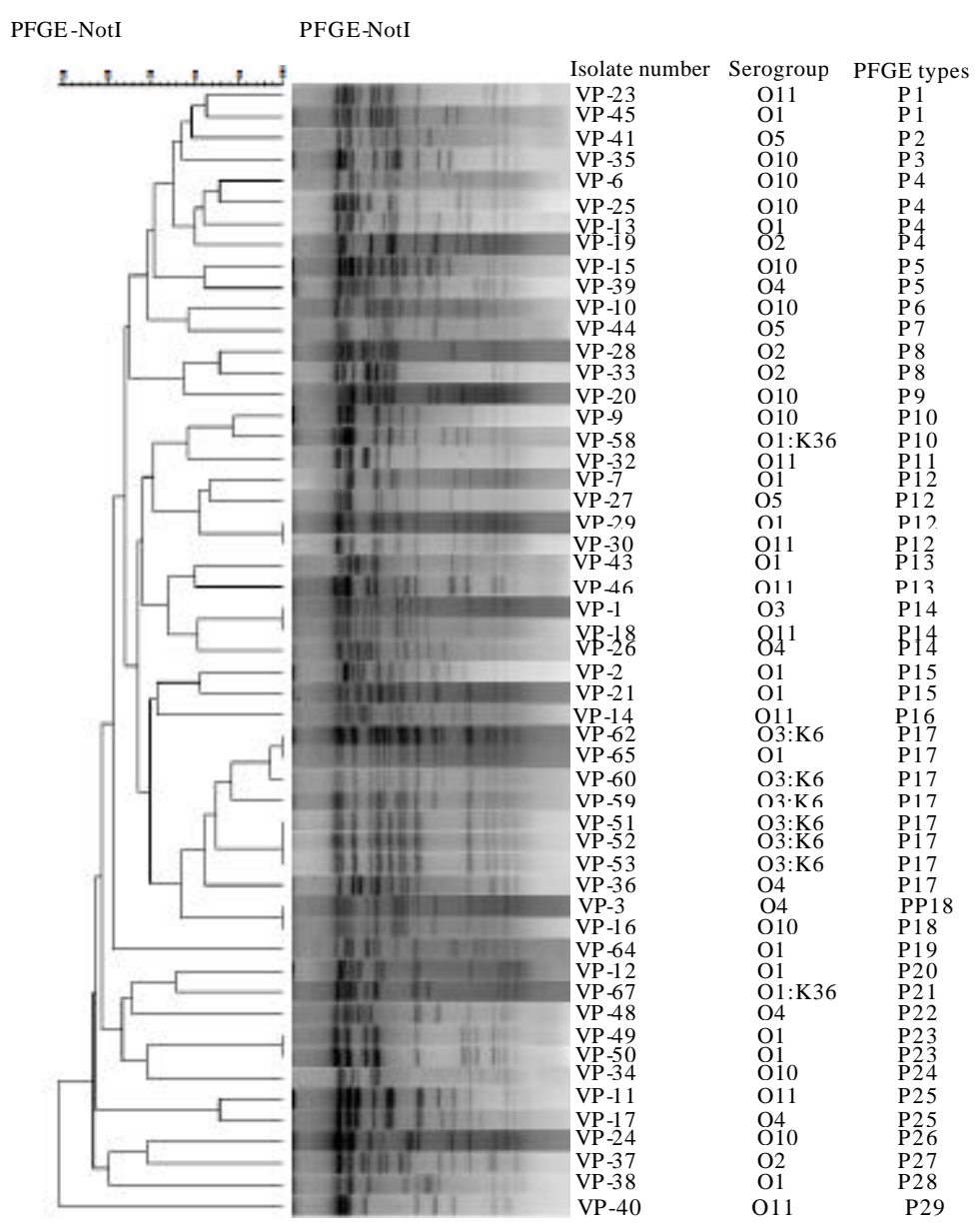

Fig. 1: Dendrogram derived from PFGE showing $53 \mathrm{~V}$. parahaemolyticus strains of different serotypes using Salmonella Braenderup as the standard

Meanwhile, CDC Department should strengthen the education to improve public's health consciousness and warn the high-risk foods earlier. Additionally, consumers also should strengthen self-consciousness by eatting less or forbidding to eat raw or undercooked seafood.

The 50 strains from shellfish belong to 7 serogroups and $\mathrm{O} 1, \mathrm{O} 4, \mathrm{O} 10$ and $\mathrm{O} 11$ were the main serogroups, accounting for $80 \%$. About 18 clinical isolates belonged to $\mathrm{O} 3, \mathrm{O} 1$ and $\mathrm{O} 4$ serogroups, accounting for $72.2,22.2$ and $5.6 \%$, respectively. Results showed that $V$. parahaemolyticus isolates from shellfish present extensive diversity in Zhoushan islands while the clinical isolates present comparatively concentrative distributing.

Pathogenic $V$. parahaemolyticus has been known to produce either Thermostable Direct Hemolysin (TDH), TDH-Related Hemolysin (TRH) or both (Miyamoto et al., 1969; Honda and Iida, 1993). Since, 1996 with the emergence of a new pandemic $\mathrm{O} 3: \mathrm{K} 6$ clone, the number of cases with $V$. parahaemolyticus infection has increased considerably in many countries (Okuda et al., 1997; Matsumoto et al., 2000). Studies showed that pandemic strains contain the orf8 gene which encodes an adherence protein that increases the ability of $V$. parahaemolyticus to adhere to host intestinal cells or the surfaces of marine plankton (Nasu et al., 2000). Several studies reported that the toxRS operon of the pandemic strains contains a unique (toxRS/new) encoding transmembrane proteins involved in the regulation of virulence associated genes (Chowdhury et al., 2000; Matsumoto et al., 2000). The presence of toxRS/new is necessary but not always sufficient whereas orf8 is sufficient but not always necessary for detection of pandemic strains (Chowdhury et al., 2000; Chao et al., 2009). In this study, the detection of tdh, toxRS/new and orf8 were all negative in 50 shellfish isolates and only 2 strains isolated in the winter contained the trh gene suggesting no pandemic 
strain in shellfish isolates in this study. However, among 18 clinical strains, 14 isolates were pandemic accouting for $77.8 \%$, of which 13 isolates belong to $\mathrm{O} 3: \mathrm{K} 6,1$ isolates belong to $\mathrm{O} 1 \mathrm{KUT}$ suggesting that a group of pandemic $\mathrm{O} 3: \mathrm{K} 6$ clone with $\mathrm{tdh}$, toxRS/new and orf8 positive spread in zhoushan islands. In addition, researchers identified $16.7 \%(3 / 18)$ non-pathogenic isolates with both tdh and trh negative in clinical isolates. As for how can these strains invade and cause human illness is still unclear. Although, pathogenic $V$. parahaemolyticus were rarely detected in environment or foodborn isolates, it doesn't mean that they are not the important epidemiological factors of food-borne diseases but just a reflection of the complexity of the $V$. parahaemolyticus in environment. Probably because the non-pathogens are more dominant than pathogens in environment, traditional method is difficult to detect the pathogens. How to improve the methods to detect the pathogens in the environment still need further research.

\section{CONCLUSION}

Pulsed-Field Gel Electrophoresis (PFGE) has been widely used as a molecular typing method to subspiecies differentiation of $V$. parahaemolyticus (Wong et al., 1996). In this study, results showed that much difference of the PFGE fingerprint map exist in the shellfish isolates suggesting they belong to several different clones with far genetic relationship. Most of the isolates display different map which demonstrate that the $V$. parahaemolyticus isolates from shellfish present extensive genetic diversity in Zhoushan islands. Two shellfish strains (VP-49, VP-50) isolated in Winter with trh positive present the same PFGE patterns, different from other's, possibly indicating that the two strains mutated to cold-resistant strains with the acquisition of coldresistant gene (Boyd et al., 2008).

In 10 clinical strains, all pandemic strains (VP-51, VP-52, VP-53, VP-59, VP-60, VP-62 and VP-65) belong to the same clone group with $82.8 \%$ similarity of which 3 strains (VP-51, VP-52, VP-53) isolated from patients of an outbreak, 4 strains (VP-59, VP-60, VP-62 and VP-65) isolated from dissemination cases of diarrhea. In these pandemic strains, a 01 KUT strain was closely related to other $03: \mathrm{K} 6$ strains suggesting that the $01: \mathrm{KUT}$ strain maybe the derivative of pandemic $\mathrm{O} 3: \mathrm{K} 6$ clone. Three non-pandemic strains (VP-58, VP-62 and VP-67) from clinical isolates however, showed significantly different genetic map from those of the universal clone of the pandemic serotype.

\section{ACKNOWLEDGEMENT}

Lihua Tang and Hongling Wang contributed equally to this research.

\section{REFERENCES}

Boyd, E.F., A.L.V. Cohen, L.M. Naughton, D.W. Ussery, T.T. Binnewies, O.C. Stine, and M.A. Parent, 2008. Molecular analysis of emergence of pandemic Vibrio parahaemolyticus. BMC Microbiol., Vol. 8. 10.1186/1471-2180-8-110.

Chao, G., X. Jiao, X. Zhou, Z. Yang, J. Huang, L. Zhou and X. Qian, 2009. Distribution, prevalence, molecular typing and virulence of Vibrio parahaemolyticus isolated from different sources in coastal province Jiangsu, China. Food Control, 20: $907-912$.

Chowdhury, N.R., S. Chakraborty, T. Ramamurthy, M. Nishibuchi, S. Yamasaki, Y. Takeda and G.B. Nair, 2000. Molecular evidence of clonal Vibrio parahaemolyticus pandemic strains. Emerg. Infect. Dis., 6: 631-636.

Cook, D.W., P. Oleary, J.C. Hunsucker, E.M. Sloan, J.C. Bowers, R.J. Blodgett and A. Depaola, 2002. Vibrio vulnificus and Vibrio parahaemolyticus in US retail shell oysters: A national survey from June 1998 to July 1999. J. Food Prot., 65: 79-87.

Depaola, A., L.H. Hopkin, J.T. P eeler, B. Wentz and R.M. Mcphearson, 1990. Incidence of Vibrio parahaemolyticus in US coastal waters and oysters. Appl. Environ. Microbiol., 56: 2299-2302.

Honda, T. and T. Iida, 1993. The pathogenicity of Vibrio parahaemolyticus and the role of thermostable direct haemolysin and related haemolysins. Rev. Med. Microbiol., Vol. 4.

Kam, K.M., C.K. Luey, M.B. Parsons, K.L. Cooper and G.B. Nair et al., 2008. Evaluation and validation of a PulseNet standardized pulsed-field gel electrophoresis protocol for subtyping Vibrio parahaemolyticus: An international multicenter collaborative study. J. Clin. Microbiol., 46: 2766-2773.

Kaneko, T. and R.R. Colwell, 1973. Ecology of Vibrio parahaemolyticus in Chesapeake Bay. J. Bacteriol., 113: 24-32.

Matsumoto, C., J. Okuda, M. Ishibashi, M. Iwanaga and P. Garg et al., 2000. Pandemic spread of an O3:K6 clone of Vibrio parahaemolyticus and emergence of related strains evidenced by arbitrarily primed PCR and toxRS sequence analyses. J. Clin. Microbiol., 38: 578-585. 
Miyamoto, Y., T. Kato, Y. Obara, S. Akiyama, $\mathrm{K}$. Takizawa and S. Yamai, 1969. In vitro hemolytic characteristic of Vibrio parahaemolyticus: Its close correlation with human pathogenicity. J. Bacteriol., 100: 1147-1149.

Nasu, H., T. Iida, T. Sugahara, Y. Yamaichi and K.S. Park et al., 2000. A filamentous phage associated with recent pandemic Vibrio parahaemolyticus $\mathrm{O} 3: \mathrm{K} 6$ strains. J. Clin. Microbiol., 38: 2156-2161.
Okuda, J., M. Ishibashi, E. Hayakawa, T. Nishino and Y. Takeda et al., 1997. Emergence of a unique O3:K6 clone of Vibrio parahaemolyticus in Calcutta, India and isolation of strains from the same clonal group from Southeast Asian travelers arriving in Japan. J. Clin. Microbiol., 35: 3150-3155.

Wong, H.C., K.T. Lu, T.M. Pan, C.L. Lee and D.Y. Shin, 1996. Subspecies typing of Vibrio parahaemolyticus by pulsed-field gel electrophoresis. J. Clin. Microbiol., 34: 1535-1539. 